\title{
Spatial structures in the heat budget of the Antarctic atmospheric boundary layer
}

\author{
W. J. van de Berg ${ }^{1}$, M. R. van den Broeke ${ }^{1}$, and E. van Meijgaard ${ }^{2}$ \\ ${ }^{1}$ IMAU, University of Utrecht, Utrecht, The Netherlands \\ ${ }^{2}$ KNMI, De Bilt, The Netherlands
}

Received: 26 July 2007 - Published in The Cryosphere Discuss.: 15 August 2007

Revised: 15 November 2007 - Accepted: 5 December 2007 - Published: 8 January 2008

\begin{abstract}
Output from the regional climate model RACMO2/ANT is used to calculate the heat budget of the Antarctic atmospheric boundary layer (ABL). The main feature of the wintertime Antarctic ABL is a persistent temperature deficit compared to the free atmosphere. The magnitude of this deficit is controlled by the heat budget. During winter, transport of heat towards the surface by turbulence and net longwave emission are the primary ABL cooling terms. These processes show horizontal spatial variability only on continental scales. Vertical and horizontal, i.e. along-slope, advection of heat are the main warming terms. Over regions with convex ice sheet topography, i.e. domes and ridges, warming by downward vertical advection is enhanced due to divergence of the ABL wind field. Horizontal advection balances excess warming caused by vertical advection, hence the temperature deficit in the ABL weakens over domes and ridges along the prevailing katabatic wind. Conversely, vertical advection is reduced in regions with concave topography, i.e. valleys, where the ABL temperature deficit enlarges along the katabatic wind. Along the coast, horizontal and vertical advection is governed by the inability of the largescale circulation to adapt to small scale topographic features. Meso-scale topographic structures have thus a strong impact on the ABL winter temperature, besides latitude and surface elevation. During summer, this mechanism is much weaker, and the horizontal variability of ABL temperatures is smaller.
\end{abstract}

\section{Introduction}

Antarctica has an extraordinary atmospheric boundary layer (ABL) climate. During the austral winter, the lowest nearsurface temperatures on Earth are observed here. The winter

Correspondence to: W. J. van de Berg

(w.j.vandeberg@phys.uu.nl) is "core-less" and in the interior it lasts from April until the end of September.

During winter, the climate of the Antarctic ABL, is determined by the absence of sunlight and the presence of the vast ice sheet. In the absence of sunlight, the net surface radiation balance becomes negative, creating a near surface temperature deficit, often referred to as "temperature inversion". In this single aspect Antarctica is not unique as similar inversions are observed in Siberia during wintertime. However, over a sloped ice sheet surface, the temperature deficit layer sets up a katabatic force. Due to the vast extent of the ice sheet, the Coriolis force is dominant over inertia and friction, and the Antarctic katabatic winds are anti-cyclonic and nearly across-slope (Van den Broeke et al., 2002). Superimposed on that, the presence of the ice sheet also introduces an anti-cyclonic large-scale circulation (Parish and Cassano, 2003). In the austral summer, when the katabatic forcing is largely restricted to the nocturnal $\mathrm{ABL}$, the topography maintains an anti-cyclonic circulation in the ABL.

Owing to friction, the horizontal ABL wind field over the ice sheet is on average divergent. A katabatic wind field in a steady state ABL over a large dome-shaped ice sheet must be divergent as long as the $\mathrm{ABL}$ is cooled by longwave radiation and sensible heat transport to the surface: the divergence of the ABL wind field initiates large-scale subsidence over the ice sheet. The meridional circulation of the Antarctic troposphere is thus characterized by a continental scale circulation cell.

In spite of the continental scale of these ABL processes, $2 \mathrm{~m}$ potential temperature (Fig. 1) varies on much smaller spatial scales. Near-surface temperatures are determined by the free atmosphere temperature, surface elevation and the ABL temperature deficit. As the free atmosphere temperature only varies on continental scales, this small scale variability must be due to differences in the ABL temperature deficit, and hence in its heat budget. Analysis of the heat budget provide a tool to understand the processes that control the

Published by Copernicus Publications on behalf of the European Geosciences Union. 


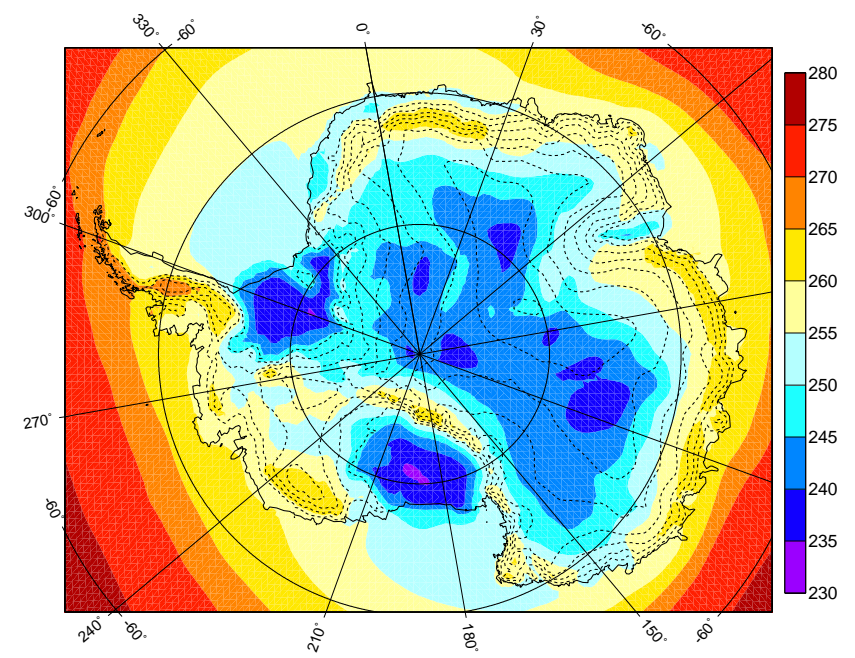

Fig. 1. Winter (JJA, 1980-2004) $2 \mathrm{~m}$ potential temperature in $\mathrm{K}$ as simulated by RACMO2/ANT.

near-surface temperature in Antarctica. Once we understand these processes, it will help us to understand how Antarctic ABL temperature might change in a future climate.

In this paper, we present the heat budget of the Antarctic ABL as simulated by a regional atmospheric climate model. Only few studies on the atmospheric heat budget of Antarctica have been published up to now. King et al. (2001) analyzed the impact of different boundary layer parameterizations on modeled temperature tendency. Van As and Van den Broeke (2006) quantified the heat budget of the summertime ABL at Kohnen station, Dronning Maud Land (DML); the geographical locations mentioned in this paper are mapped in Fig. 2. Van de Berg et al. (2007) presented an analysis of the modeled heat budget of East Antarctica, but with a focus on vertical distribution and the dependency on elevation and distance to the coast. In this paper, we will focus on horizontal spatial patterns within the ABL over the entire ice sheet, thus including West Antarctica and the Antarctic Peninsula.

In the next section, a brief description of the atmospheric model is given. Then, in Sect. 3, the heat budget equation is formulated and a suitable ABL depth is defined. Next, the results for winter (JJA) and summer (DJ) are presented in Sects. 4 and 5, respectively. The paper ends with conclusions.

\section{Model description and evaluation}

The regional atmospheric climate model RACMO2/ANT is used for this study. This model consists of the dynamics of the limited area model HiRLAM, version 5.0.6 (Undén et al., 2002) and the physics of the European Centre for Medium Range Weather Forecasts (ECMWF) model, cycle CY23R4 (White, 2001). The physics package has been adjusted to better represent Antarctic conditions, namely, a slower decaying

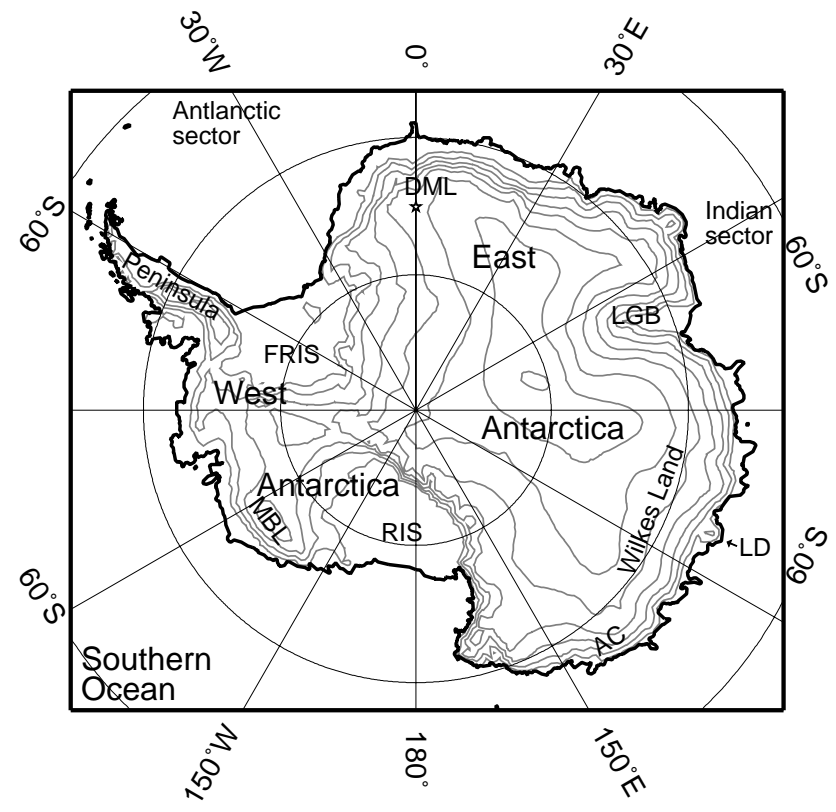

Fig. 2. Map of Antarctica. The star locate Kohnen Station. DML, LGB, LD, AC, RIS, MBL and FRIS denote Dronning Maud Land, Lambert Glacier Bassin, Law Dome, Adélie Coast, Ross Ice Shelf, Marie Byrd Land and Filchner-Ronne Ice Shelf, respectively.

snow albedo, reduced roughness lengths of heat and moisture, improved snow pack representation, time-dependent greenhouse gasses concentrations and enhanced generation of solid precipitation for freezing conditions. In the dynamics package the artificial horizontal diffusion of moisture has been reduced.

During the model integration, the lateral boundaries of RACMO2/ANT are relaxed to six-hourly atmospheric states from ECMWF Re-Analysis (ERA-40) for September 1957 to August 2002. The integration is extended with ECMWF operational analyses until the end of 2004. Also, daily sea ice cover and sea surface temperature are taken from these sources. The interior of the model is allowed to evolve freely. Since the ERA-40 climatology prior to 1979 has insufficient quality in the Southern Hemisphere (Bromwich and Fogt, 2004; Sterl, 2004), only data from the period December 1979 until the end of 2004 is used here.

Reijmer et al. (2005) and Van de Berg et al. $(2006,2007)$ evaluated RACMO2/ANT output, and concluded that the model realistically simulates the climate of Antarctica, except that surface sensible heat fluxes and downwelling radiation fluxes over the ice sheet are over- and underestimated by about $20 \mathrm{~W} / \mathrm{m}^{2}$, respectively. This model shortcoming should be kept in mind for in the remainder of this paper.

To assess the quality of the model simulated radiation, topof-atmosphere (TOA) radiative fluxes are compared with observations from the International Satellite Cloud Climatology Project (ISCCP, Zhang et al., 2004). Figure 3 shows TOA net radiation observations and the simulated flux, for 
winter (JJA, a) and summer (DJ, b), both for the period 1983 to 2004.

During winter, modeled net radiation at TOA, which is predominantly determined by longwave (LW) emission, deviates less than $10 \mathrm{~W} / \mathrm{m}^{2}$ from observations over the ice sheet (Fig. 3a). Over the Southern Ocean, the deviations are larger, caused by overestimated LW emission, while short-wave (SW) net insolation is well simulated. Deviations are larger over the ice sheet in summer (Fig. 3b), mainly due to the underestimation of SW absorption by about $30 \mathrm{~W} / \mathrm{m}^{2}$. Simulated LW emission matches observations within $10 \mathrm{~W} / \mathrm{m}^{2}$. Over the Southern Ocean south of $60^{\circ} \mathrm{S}$, both SW and LW are well simulated. The results in Fig. 3a indicates that the net cooling/warming of the atmospheric column by radiation is well simulated during winter. Net summer TOA fluxes are less accurately simulated, and subsidence could therefore be found overestimated in summer.

\section{Methods}

\subsection{Definition of the heat budget}

Van de Berg et al. (2007) presented the heat budget equation, which is

$$
\begin{aligned}
\underbrace{\frac{\partial T}{\partial t}-\frac{1}{\rho c_{p}} \frac{\partial p}{\partial t}}_{L T T}= & -\underbrace{\boldsymbol{u} \cdot\left(\nabla T-\frac{1}{\rho c_{p}} \nabla p\right)}_{A d v H+A d v V}+K-\underbrace{\frac{1}{\rho c_{p}} \frac{\partial S W}{\partial z}}_{S W D} \\
& -\underbrace{\frac{1}{\rho c_{p}} \frac{\partial L W}{\partial z}}_{L W D}-\underbrace{\frac{1}{\rho c_{p}} \frac{\partial S H F}{\partial z}}_{S H D}-\underbrace{\frac{1}{\rho c_{p}} \frac{\partial C H F}{\partial z}}_{C H D}+Q,
\end{aligned}
$$

where $L T T$ is the local temperature tendency, i.e. the heat uptake due to temperature changes. On monthly time-scales $L L T$ is a negligible contribution. $A d v H$ and $A d v V$ are the "horizontal", i.e. along-slope, and vertical heat advection, respectively. Both terms are calculated using six-hourly model states; they capture only heat advection on length scales that are resolved by the model. AdvH is derived along the hybrid $\eta$-coordinate of the model. The $\eta$-coordinate closely follows the topography in the atmospheric boundary layer (ABL) and is relaxed to pressure levels in the free atmosphere. $K$ represents numerical diffusion that is applied for numerical stability. The external heating terms $S W D$ and $L W D$ represents the divergence of short-wave and long-wave radiation fluxes, respectively. Heating by divergence of the sensible heat flux $(S H F)$ is indicated by $S H D$. Convective heat fluxes $(C H F)$ are parameterized separately in RACMO2/ANT; $C H D$ is heating by divergence of $C H F$. Finally, $Q$ represents heating or cooling by various water phase changes like condensation, evaporation of falling precipitation or melt of falling snow. $S W D, L W D, S H D$ and $C H D$ are derived from monthly accumulated flux profiles of $S W, L W, S H F$ and $C H F$, respectively. $Q$ is derived from monthly precipi-
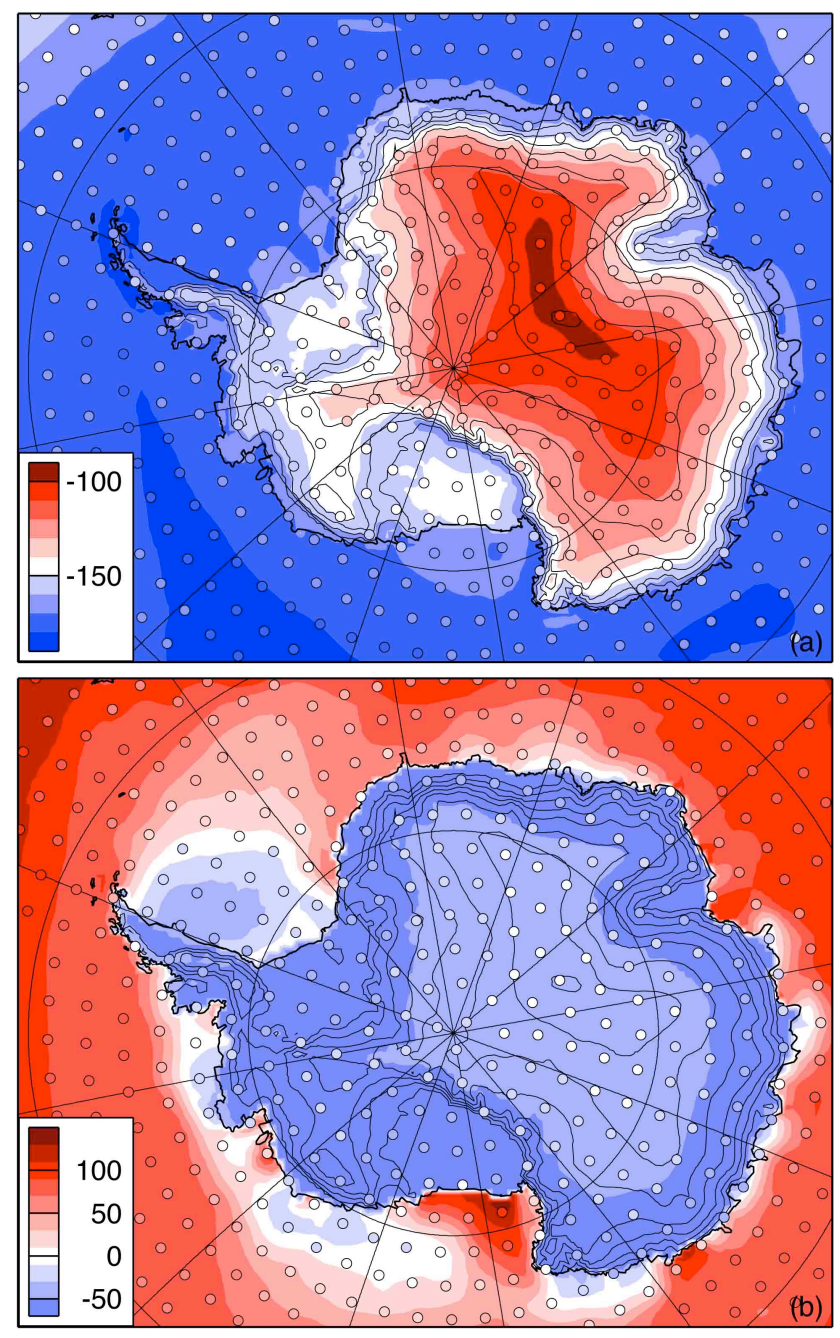

Fig. 3. Comparison of observed (circles, Zhang et al., 2004) and simulated TOA net radiative emission $\left(\mathrm{W} / \mathrm{m}^{2}\right.$ ) for 1983 to 2004 , for (a) Winter (JJA) and (b) Summer (DJ). The observations represent a spatial continuous field but are shown as points for the comparison. Positive values indicate net fluxes into the atmosphere.

tation fluxes, cloud content advection and temporal changes in cloud content.

The validity of this approach has been checked by using one year of model output in which the accumulated temperature tendency corresponding to numerical diffusion and physics, and the heating/cooling coming from water phase changes had all been explicitly stored. The calculated heat budgets are found to match these accumulated temperature tendencies well.

In the graphic presentation of ABL mean heat budgets hereafter, $K$ has been included in $A d v V$. We did so because RACMO2/ANT is a hydrostatic model; vertical winds are thus not explicitly calculated. Numerical diffusion is required for model stability, but at locations where the slope of the topography changes, diffusion generates a secondary 

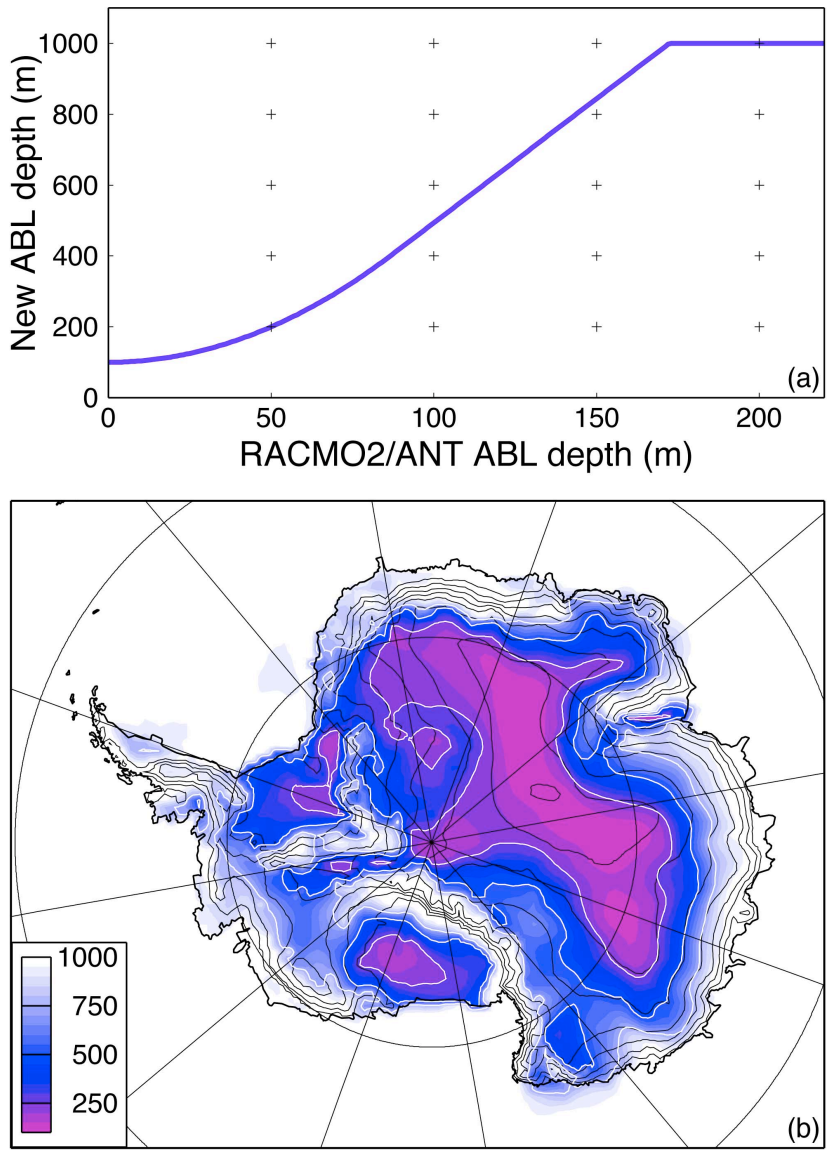

Fig. 4. (a) Scaling function from RACMO2/ANT ABL depth to new ABL depth. (b) Average wintertime ABL depth in $\mathrm{m}$.

flow which is balanced by the vertical wind. As a result, vertical advection and diffusion show counterbalancing smallscale patterns that have no physical meaning. If $K$ is added to $A d v V$, these patterns disappear. Since the numerical diffusion is derived as a residual, summing implies that we regard $A d v V$ as a residual of all other processes. Another method to remove these patterns is by smoothing of $A d v V$, it would give results similar to those presented here.

\subsection{Definition of free atmosphere parameters}

The background temperature $\left(\theta_{0}\right)$ is derived by downward extrapolation of the free atmosphere temperature gradient. The large-scale wind $\left(\boldsymbol{u}_{l s c}=\left(u_{l s c}, v_{l s c}\right)\right)$ is then derived by vertical extrapolation of the free atmosphere wind assuming a thermal wind balance with $\theta_{0}$, namely

$$
\begin{aligned}
& \frac{\partial u_{l s c}}{\partial \ln p}=+\frac{R_{d}}{f}\left(\frac{p}{p_{0}}\right)^{\frac{R_{d}}{c_{p}}} \frac{\partial \theta_{0}}{\partial y} \\
& \frac{\partial v_{l s c}}{\partial \ln p}=-\frac{R_{d}}{f}\left(\frac{p}{p_{0}}\right)^{\frac{R_{d}}{c_{p}}} \frac{\partial \theta_{0}}{\partial x},
\end{aligned}
$$

with $p_{0}=1013.25 \mathrm{hPa} . \theta_{0}$ and $\boldsymbol{u}_{l s c}$ are calculated on monthly means. The temperature deficit $(\delta \theta)$ and the ABL wind $(\delta \boldsymbol{u})$ are defined as the deviation from the background temperature and large-scale wind, respectively.

\subsection{Definition of ABL depth}

There are many definitions of the depth of the stable ABL (Stull, 1988). Here we utilize a definition of the ABL depth that satisfies the following requirements:

a) It should be large enough to include the main part of the temperature deficit layer, where $\theta$ deviates significantly, i.e. more than $1 \mathrm{~K}$, from the free atmosphere $\theta_{0}$.

b) It should be large enough to include the katabatic wind layer. As these winds are forced by $\delta \theta$, this is equivalent to a).

c) It should include the turbulent layer, where $S H F$ is nonzero.

Ideally, the depth of the ABL is defined using one or all of these requirements, but that did not provide a continuously defined ABL depth in both space and time. For example, the temperature deficit is poorly constrained during summer and over ice free ocean. Therefore, we used the depth of the ABL as diagnosed by RACMO2/ANT. It is defined as the level where the bulk Richardson number reaches 0.25 of its surface value. This field is continuous in space and time, but ABL depths are far below the typical temperature inversion height. In order to satisfy the requirement listed above, we scaled monthly mean diagnosed ABL depth applying the transformation shown in Fig. 4a. Figure 4b shows the resulting mean wintertime (JJA) ABL depth. Typical ABL depths thus obtained range from $100 \mathrm{~m}$ on the East Antarctic plateau up to $1 \mathrm{~km}$ near the coast and over the Southern Ocean. In the remainder of this paper, we will present point-wise calculated heat budget components averaged over this ABL depth.

\subsection{Example of vertical profiles}

Van de Berg et al. (2007) presented vertical profiles of the East Antarctic heat budget averaged in $500 \mathrm{~m}$ elevation bins. Figure 5 is an example of such profiles, it shows the winter (JJA) heat budget for the East Antarctic middle escarpment between 1750 and $2250 \mathrm{~m}$ a.s.1. The horizontal green lines shows the mean ABL depth as used in this paper. Its depth is chosen such that it contains the layer that interacts most strongly with the surface. This elevation bin is characterized by strong katabatic winds and a deep temperature deficit layer (Fig. 5a). The surface energy budget (Fig. 5b) is a simple balance between net longwave radiation emission and $S H F$ that is directed towards the surface. Figure 5c shows the resulting profiles of the heat budget components, which is remarkably complex. Cooling of the ABL occurs 

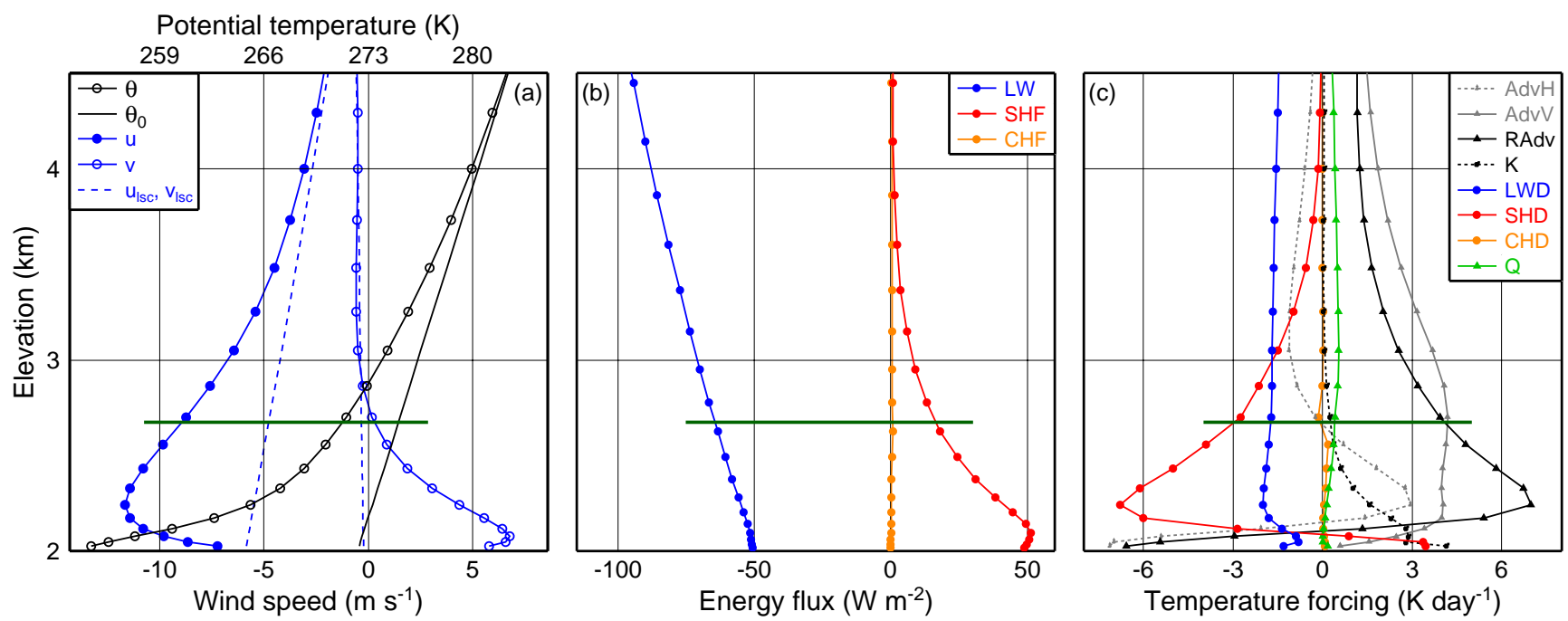

Fig. 5. Winter (JJA) vertical profiles, binned for the middle escarpment of East Antarctica (1750 and $2250 \mathrm{~m}$ a.s.1.) of (a) potential temperature $(\theta)$, background potential temperature $\left(\theta_{0}\right)$, cross-slope $(u)$ and along-slope $(v)$ wind, and their large scale components $\left(u_{l s c}\right.$, $v_{l s c}$ ), (b) $L W, S H F$ and $C H F$, (c) the heat budget terms. $R A d v$ is the sum of $A d v H$ and $A d v V$. The horizontal dark green line in (a), (b) and (c) indicates the average depth of the ABL for this bin.

primarily by $L W D$ and $S H D$. This cooling is mainly compensated by $A d v V$ and to a lesser extent by $A d v H$. Noteworthy is the sign reversal of $A d v H$ and $S H D$ in the lowest approximately $100 \mathrm{~m}$, related to the downward transport of cold air from the plateau (Van de Berg et al., 2007). $K$ is separated from $A d v V$ only in this figure.

\section{Results: winter}

\subsection{External heating and surface interactions}

Figure 6 shows winter (JJA) ABL forcings by $S H D, L W D$ and $Q$. Of those three, $S H D$ is the dominant cooling term. At the surface in Antarctica, $S H F$ approximately balances net $L W$ cooling. This heat is extracted from the ABL. In the interior of East Antarctica, the ABL is shallow (Fig. 4b). The divergence of $S H F$, thus cooling by $S H D$, is therefore largest in these regions, typically $10 \mathrm{~K}$ per day (Fig. 6a), even though the surface flux is relatively small, typically $30 \mathrm{~W} \mathrm{~m}^{2}$. Near the coast, the ABL is deeper, forcing $S H D$ cooling rates to be low in spite of the larger surface value of $S H F$.

The ice free part of the Southern Ocean acts as an enormous source of sensible heat during winter, inducing a positive $S H D$. Closer to the continent, a persistent and nearcomplete sea-ice cover isulates the atmosphere from the warm ocean water, so $S H D$ is strongly reduced or becomes even slightly negative in the sea ice zone, but still remains less than $-0.8 \mathrm{~K}$ per day.

Cooling of the ABL by $L W D$ (Fig. 6b) is generally one order of magnitude smaller than by $S H D$. Maximum $L W D$ cooling rates are found over the domes of East Antarctica, where the ABL is shallow. On the domes, the surface temperature deficit is large, but decreases steeply with height. As a result, the top of the ABL is warmer in absolute sense than the free atmosphere above and the surface below, which explains the relatively large cooling rates. Locations with a deep ABL have in general least cooling by $L W D$, because at these points the temperature maximum is less outspoken.

Figure 6c shows that $Q$ is generally insignificant over the main ice sheets in Antarctica. Exceptions are those regions with high precipitation rates, namely, the west coast of the Antarctic Peninsula, coastal Marie Byrd Land and the east side of Law Dome in Wilkes Land. Heating by condensation is also a discernible heat source in the ABL of the Southern Ocean. Further north the melt of falling snow becomes dominant, and $Q$ becomes negative.

The contribution of $C H D$ to the heat budget (not shown) is very small during winter. It warms the ABL by up to $2 \mathrm{~K}$ per day over the ice-free ocean, elsewhere its contribution is near-zero.

As noted in Sect. 2, surface downwelling $L W$ radiation and $S H F$ are under- and overestimated by RACMO2/ANT, respectively. This implies an overestimation of the cooling of the ABL by $S H D$. Since most of the downwelling $L W$ at the surface is emitted by the ABL, and LW fluxes at the top of the atmosphere (TOA) are found to match well with observations, the underestimation of the TOA-to-surface LW divergence probably implies an underestimation of cooling of the ABL by $L W D$. Model errors in $L W D$ and $S H D$ therefore partly even out in the heat budget. 

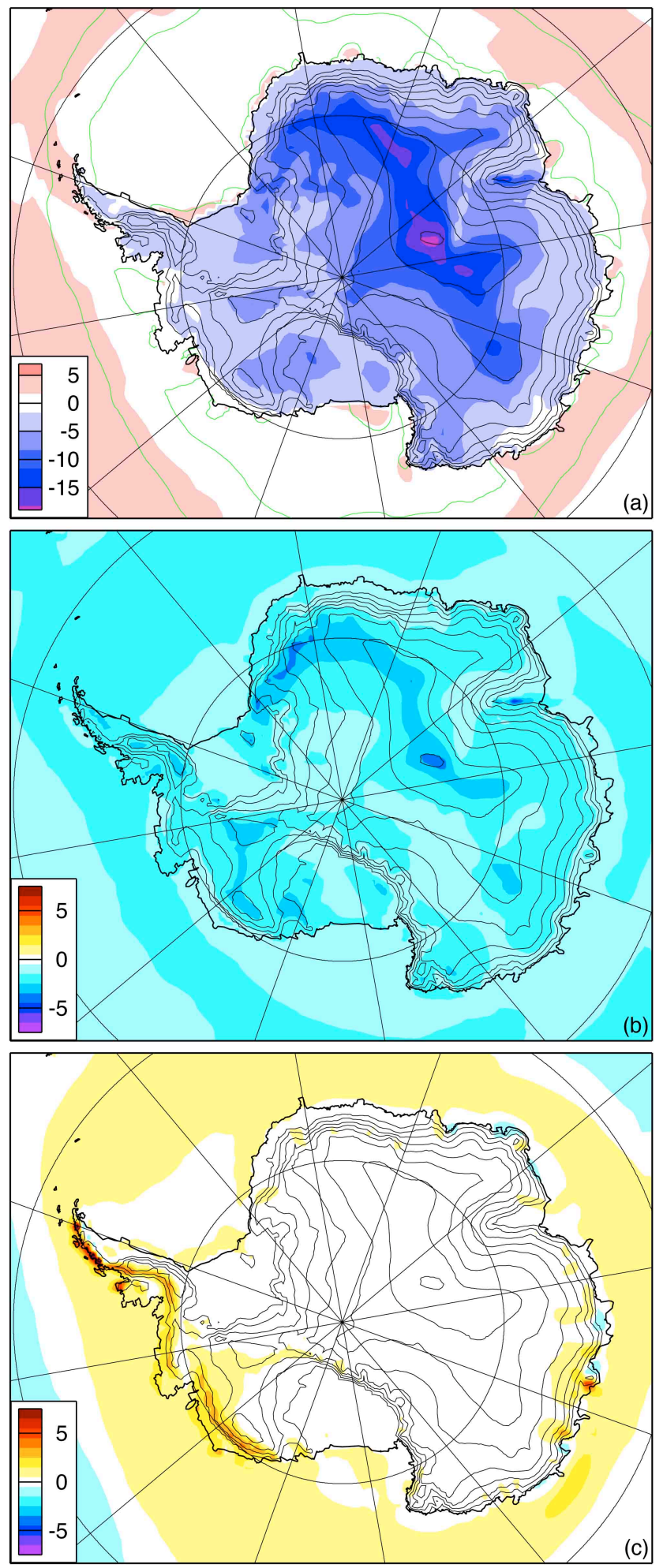

Fig. 6. Average winter ABL temperature forcing by (a) $S H D$, (b) $L W D$ and (c) $Q$ in K per day. 20 and $90 \%$ sea ice cover isopleths are drawn in green in (a).

\subsection{Heat advection in East Antarctica}

From the previous section it is clear that the energy extracted from the ABL by $S H D$ and $L W D$ must be balanced by horizontal and vertical heat advection. The spatial variability of the total heat advection in the ABL ( $A d v H+A d v V$, not shown) is only significant on continental scales. This must be so, since $S H D$, the main ABL heat sink, is also spatially smooth (Fig. 6a). Evidently, the inner product of the 3-D wind field with horizontal and vertical temperature gradients determine the magnitude of the heat advection. In order to better understand the more complicated regional patterns of $A d v H$ and $A d v V$, vertical profiles averaged for East Antarctica are discussed first in this section.

Figure 7 shows average profiles of potential temperature, along-slope and vertical wind, horizontal and vertical advection for East Antarctica $\left(30^{\circ} \mathrm{W}-150^{\circ} \mathrm{E}\right)$. The surface temperature deficit is a prominent feature of the ABL in East Antarctica (Fig. 7a) and it is strongest in the interior. Note that height is given as $\mathrm{m}$ above the surface level. As a result, the rise of free the atmosphere potential temperature towards the interior is due to increasing surface elevation in a stably stratified atmosphere. In the interior, however, this effect is almost balanced by the effect of decreasing latitude; potential temperature isopleths are thus almost parallel to the surface.

$A d v V$ (Fig. 7b) is the main heating term in the atmosphere over the interior of East Antarctica through subsidence ( $w<0$, contours in Fig. 7b). Warming by $A d v V$ extends all the way downwards to the surface, which indicate that the ABL wind field over East Antarctica is divergent on average. This is in line with the general picture of katabatic outflow. The largest heating rates are found in the interior, a result of the strong vertical temperature gradients in the ABL. Over the coastal slopes of East Antarctica, upward motion is found on average, due to piling up of out-flowing cold air. Diffusion $(K)$ is included here in $A d v V$, it sole contribution is the near surface warming at the ice sheet margin, which is related to diffusion of the persistently large temperature difference between the ice shelf and the ocean.

The $A d v H$ patterns (Fig. 7c) mainly reflect the changes in the depth and temperature inversion strength in the ABL. The wind has a significant friction-driven downslope component in the ABL (Van den Broeke and Van Lipzig, 2003), with maximum values near the surface about $250 \mathrm{~km}$ inland. In the interior of Antarctica, warming by $A d v H$ is related to the deepening of the inversion layer. $A d v H$ becomes a cooling term near the surface in the escarpment, where strong vertical turbulent mixing, driven by katabatic wind, reduces vertical temperature gradients in the ABL. This reverses the near-surface horizontal temperature gradient compared to the interior. Averaged over the depth of the ABL, upper-level heating and low-level cooling by $A d v H$ thus partly cancel in the escarpment (see also Fig. 5c). Cold air accumulates at the foot of the continent, because the katabatic force vanishes over the flat sea ice surface. Here, AdvV cools the 
air by rising motion. As a result, the katabatic outflow from Antarctica is relatively warm, which drives the strong heating by $A d v H$ in this region.

\subsection{Spatial distribution of $A d v H$ and $A d v V$}

Figure 8 shows potential temperature and wind (a), $A d v V$ (b) and $A d v H$ (c) averaged over the ABL depth. The magnitudes of $A d v V$ and $A d v H$ clearly exceed those of the other heat budget terms in Fig. 6. Superimposed on the continental-scale advection processes described in the previous section, surprisingly fine-scale spatial patterns are visible. These are topographically induced, and can be explained as follows: The ABL mean wind (Fig. 8a) generally follows the ice sheet height contours, but the curvature of the elevation contours has a distinct impact on the relative wind direction. Convex elevation contours, at domes and ridges, for example, at $135^{\circ} \mathrm{E}, 70^{\circ} \mathrm{S}$, enhance horizontal divergence of the ABL wind field and promote downward vertical motion. Figure $8 \mathrm{~b}$ clearly shows that in the interior East Antarctica, ridges and domes have maximum heating rates by $A d v V$. Conversely, concave elevation contours, for example at 0 $30^{\circ} \mathrm{E}, 82^{\circ} \mathrm{S}$, induce a converging $\mathrm{ABL}$ wind field and enhance upward motion. As Fig. 8b shows, this effect is strong enough in some places to change subsidence into upward motion, making $A d v V$ a cooling term. AdvV reaches its extreme positive values in valleys and ridges with length scales of $100 \mathrm{~km}$, which is the minimum length that is properly resolved by the model grid.

Figures $8 \mathrm{~b}$ and $\mathrm{c}$ show that $A d v V$ and $A d v H$ counterbalance in many regions. The primary reason is that $A d v H$ tends to remove temperature gradients that are generated by $A d v V$. As a result, locations with distinct convex topography have a large negative $A d v H$, for example $60^{\circ} \mathrm{E}, 70^{\circ} \mathrm{S}$. For the same reason, maximum heating rates by $A d v H$ are found at concave topography, for example $0-30^{\circ} \mathrm{E}, 82^{\circ} \mathrm{S}$. Furthermore, positive $A d v H$ values are found where the ABL flow is pointed southwards (e.g. Southern DML) or into ice shelves. Although the topography of DML is convex, no large-scale cooling by $A d v H$ is found here. It shows that cooling by $A d v H$ requires an upstream reservoir of cold air. In contrast to most of East Antarctica, such a reservoir is absent in DML.

As for $A d v V$, extreme values of $A d v H$, and thus the largest along-slope temperature gradients, are found at topographic structures with length scales in the order of $100 \mathrm{~km}$. On the other hand, larger features may have a smaller temperature gradient, but provide a longer path for $A d v H$ to act on temperature.

The coast of West Antarctica and the western side of the Antarctic Peninsula experience cooling by $A d v H$ due to diabatic uplift in a stably stratified atmosphere. Only in these regions, heating by $Q$ (Fig. 6c) is significant. Since $A d v H$ is calculated using adiabatic trajectories, diabatic uplift along the topography is equivalent with a negative $\operatorname{AdvH}$.
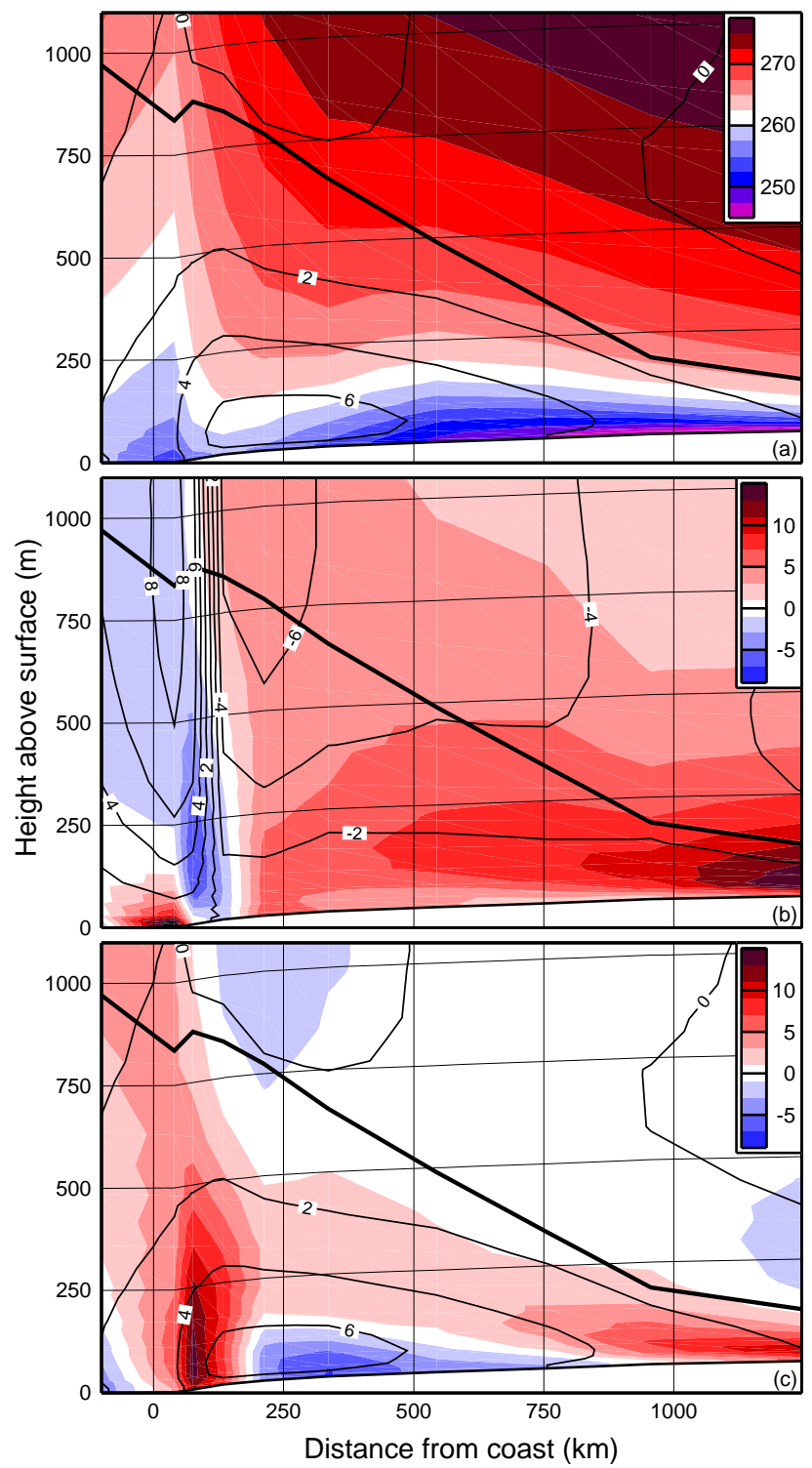

Fig. 7. Mean winter profiles for the East Antarctic sector between $30^{\circ} \mathrm{W}$ and $150^{\circ} \mathrm{E}$. (a) potential temperature (colors in $\mathrm{K}$ ) and along-slope wind (contours, $\mathrm{m} / \mathrm{s}$ ); (b) Vertical heat advection $(A d v V)$ (colors, $\mathrm{K}$ per day) and vertical wind (contours, $\mathrm{mm} / \mathrm{s}$ ); (c) Horizontal (along-slope) heat advection $(A d v H)$ (colors, $\mathrm{K}$ per day) and along-slope wind (contours, $\mathrm{m} / \mathrm{s}$ ). In all three figures, the surface elevation is schematically included for orientation. The thick black line represents the average ABL depth.

4.4 Synoptic and persistent large-scale and ABL contributions to $A d v H$

As mentioned above, $A d v H$ is directly determined by horizontal temperature gradients and the ABL wind field, as shown in Fig. 8a. In $A d v H$, five contributions can be distinguished, as listed in Table 1. First, horizontal heat advection by variability on synoptical time scales $\left(A d v H_{S T}\right)$ 

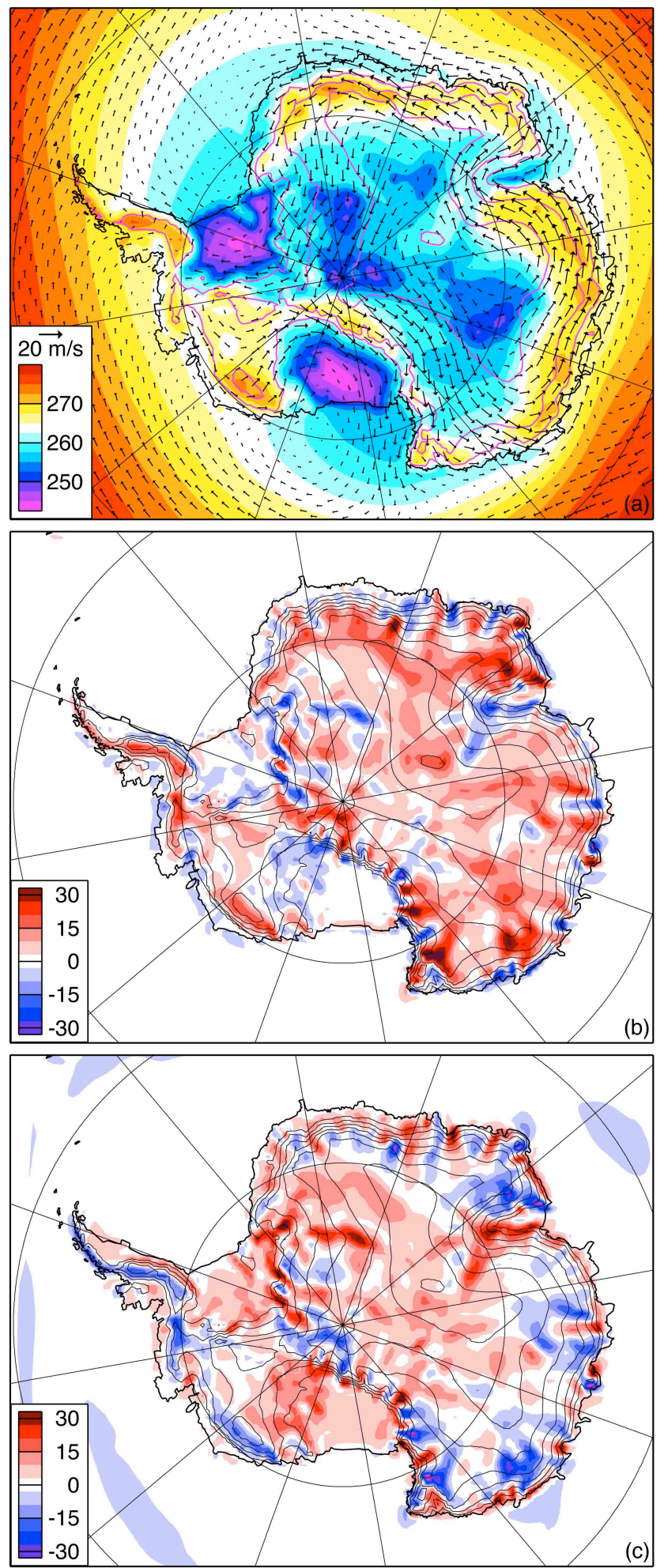

Fig. 8. Winter averages of (a) ABL mean potential temperature $(\mathrm{K})$ and wind (b) Vertical heat advection $(A d v V)$ in $\mathrm{K}$ per day (c) Horizontal (along-slope) heat advection $(A d v H)$ in $\mathrm{K}$ per day.
Table 1. Contributions to $A d v H$.

\begin{tabular}{|c|c|c|}
\hline Abbreviation & product & Horizontal heat advection by: \\
\hline$A d v H_{S T}$ & & $\begin{array}{l}\text { Synoptical wind and temperature } \\
\text { variability }\end{array}$ \\
\hline$A d v H_{P}$ & & $\begin{array}{l}\text { Persistent, monthly mean winds } \\
\text { and temperature }\end{array}$ \\
\hline$A d v H_{\boldsymbol{u}_{l s c} \theta_{0}}$ & $\boldsymbol{u}_{0} \cdot \nabla \theta_{0}$ & $\begin{array}{l}\text { Large scale wind and background } \\
\text { temperature }\end{array}$ \\
\hline$A d v H_{\boldsymbol{u}_{l s c} \delta \theta}$ & $\boldsymbol{u}_{0} \cdot \nabla \delta \theta$ & $\begin{array}{l}\text { Large scale wind and temperature } \\
\text { deficit }\end{array}$ \\
\hline$A d v H_{\delta \boldsymbol{u} \theta_{0}}$ & $\delta \boldsymbol{u} \cdot \nabla \theta_{0}$ & $\begin{array}{l}\text { ABL wind and background tem- } \\
\text { perature }\end{array}$ \\
\hline$A d v H_{\delta \boldsymbol{u} \delta \theta}$ & $\delta \boldsymbol{u} \cdot \nabla \delta \theta$ & $\begin{array}{l}\text { ABL wind and temperature } \\
\text { deficit }\end{array}$ \\
\hline
\end{tabular}

is separated from horizontal heat advection by persistent wind and temperature patterns $\left(A d v H_{P}\right)$. Second, following Van den Broeke et al. (2002); Van den Broeke and Van Lipzig (2003) and Van de Berg et al. (2007), the large-scale, thus background free-atmosphere, and ABL contributions to the temperature and wind profiles are isolated in the persistent wind and temperature patterns. For an example of the profiles of $\theta_{0}, \delta \theta, \boldsymbol{u}_{l s c}$ and $\delta \boldsymbol{u}$ see Fig. 5a. Four contributions to $A d v H_{P}$ are distinguished from these two pairs of wind and temperature fields.

\subsubsection{Synoptic and persistent contributions to $A d v H$}

$A d v H_{P}$ (Fig. 9a) is calculated using monthly mean temperature and wind fields, whereas $A d v H_{S T}$ (Fig. 9b) is calculated using six-hourly deviations of the monthly mean winds and temperatures.

The similarity between total $A d v H$ (Fig. 8c) and $A d v H_{P}$ is high, $A d v H_{S T}$ is generally one order of magnitude smaller. Since topographically driven wind field divergence/convergence is a near stationary process, it is expected that $A d v H$ in Antarctica is primarily due to persistent wind and temperature patterns. This is only so because Antarctica has an extreme ABL climate, in which $A d v H$ locally exceeds heating rates of $1 \mathrm{~K}$ per hour. Only in Antarctica significant and persistent temperature gradients are found along the prevailing wind. Elsewhere on Earth, $A d v H$ averaged over longer time-scales is at least one order of magnitude smaller, because temperature gradients along the dominant wind become small after a while. Outside of Antarctica, $A d v H_{S T}$ can thus be easily as significant as $A d v H_{P}$, if not larger. Some patterns can be recognized in $A d v H_{S T}$ (Fig. 9b). In the ABL over the East Antarctic plateau and over the Ross and Filchner-Ronne Ice Shelves, $A d v H_{S T}$ is heating, and in the coastal zone it is cooling. The spine of the Antarctic Peninsula has the highest cooling rates, due to the difference in lapse-rate of wet-adiabatic ascents and dry-adiabatic 

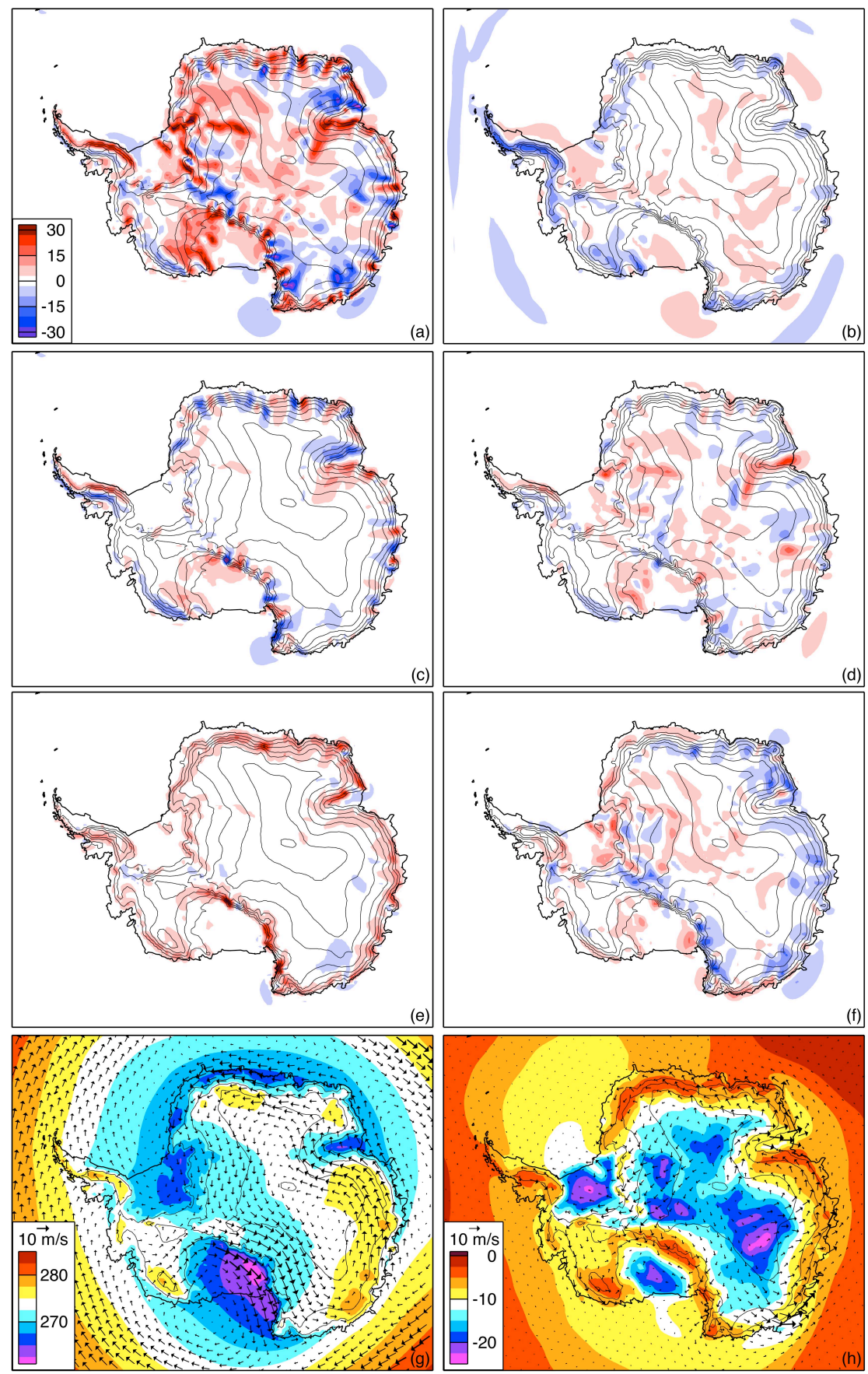

Fig. 9. Decomposition of winter horizontal (along-slope) heat advection ( $A d v H$ ) into its various contributions (Table 1) in K per day: (a) monthly mean temperature and winds; (b) short time-scale variability; (c) large-scale circulation and background temperature profile; (d) large-scale circulation and temperature deficit; (e) ABL winds and background temperature profile; (f) ABL winds and temperature deficit. (g) Large-scale winds on background potential temperature in $\mathrm{K}(\mathbf{h})$ ABL residual wind on temperature deficit in $\mathrm{K}$.

descents. In contrast to many other high accumulation sites in Antarctica, the directional persistency of the wind is low over the Peninsula, therefore the net heat advection becomes part of $A d v H_{S T}$. Cold air advection is also found on the edges of the sea-ice zone.

\subsubsection{Large-scale and ABL contributions to $A d v H$}

The winter-mean ABL temperatures and winds (Fig. 8a) are decomposed in free-atmosphere contributions (Fig. 9g) and ABL components (Fig. 9h). Figure 9g shows the ABL mean background potential temperature $\left(\theta_{0}\right)$ and the large-scale 

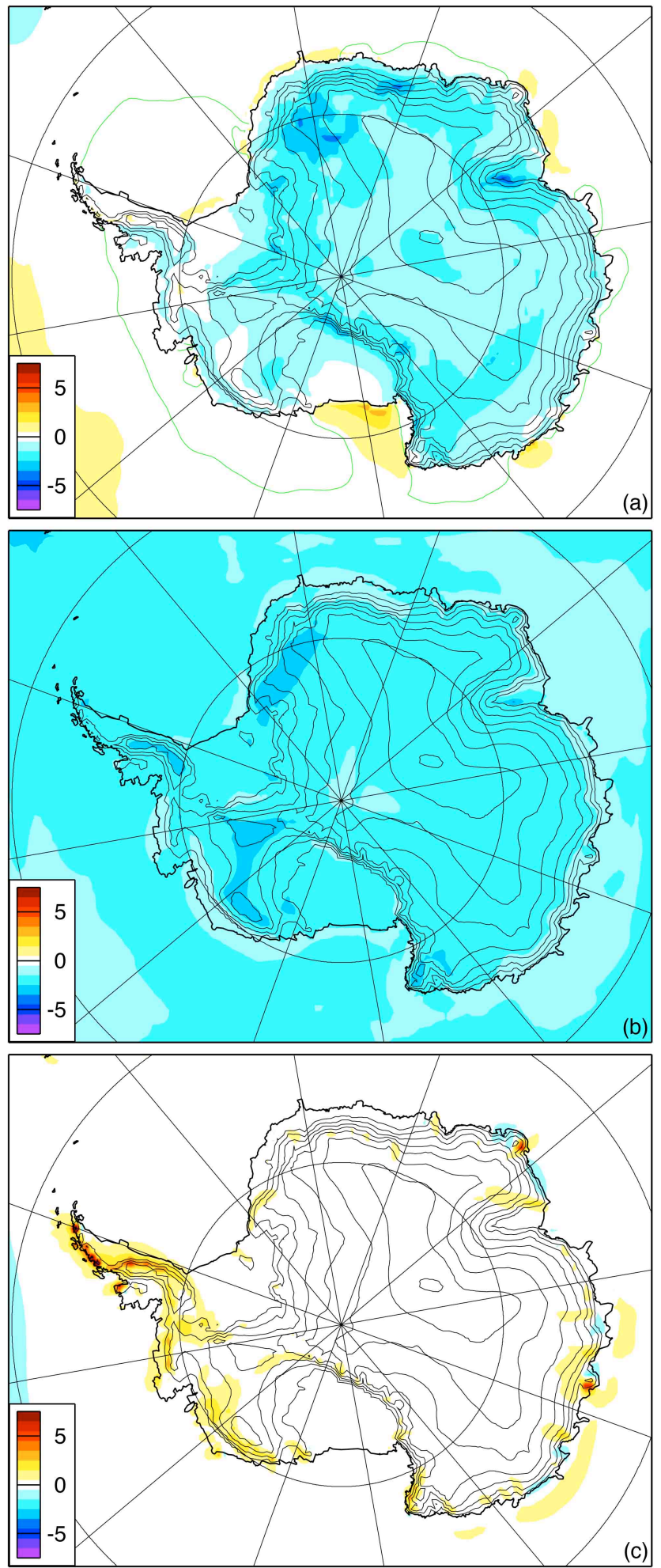

Fig. 10. Average summer boundary layer temperature forcing by (a) $S H D$, (b) $L W D$ and (c) $Q$ in K per day. $50 \%$ sea ice cover isopleths are drawn in green in (a). wind vector $\boldsymbol{u}_{l s c} . \quad \theta_{0}$ is mainly a function of latitude and elevation. As a result, the ice shelves have low $\theta_{0}$, while northward extending parts of East and West Antarctica have relatively high $\theta_{0}$. The sector between 100 and $160^{\circ} \mathrm{E}$ of the Southern Ocean is relatively warm, while the Atlantic sector is colder. The large-scale circulation consists of westerly winds around Antarctica turning into easterlies over East Antarctica. Quasi-stationary cyclonic cells can be found on the Ross and Filchner-Ronne Ice Shelves and off the coast of Wilkes Land. As was pointed out by Van den Broeke and Van Lipzig (2003), $\boldsymbol{u}_{l s c}$ closely follows the large-scale topography of the ice sheet, reflecting the influence of the ice sheet on the troposphere large-scale circulation through the thermal wind balance.

Figure 9h shows the ABL mean temperature deficit $(\delta \theta)$ and ABL wind vectors $(\delta \boldsymbol{u})$. Over the ocean, the ABL temperature deficit is restricted to the sea ice covered areas, and vanishes over open water. Over the ice sheet, the dependency of the temperature deficit on topographic curvature is clearly visible: Convex topographic features have a weak inversion, while the temperature deficit is larger over concave topography. ABL winds are mainly katabatic, and therefore weak over the sea ice. The importance of friction is apparent from the relative down-slope direction of the vectors. Strongest $\mathrm{ABL}$ winds are found in the major ABL outflow locations in East Antarctica, i.e. Adélie Coast and west of the Lambert Glacier Basin.

Figure 9c shows heat advection by the large-scale wind and the background temperature $\left(A d v H_{u_{l s c} \theta_{0}}\right)$. This term highlights the alternating cooling and warming patches in the coastal zone, located at the upwind and downwind side, respectively, of small scale $(\sim 100 \mathrm{~km})$ topography. It shows that the large-scale circulation does not follow these smaller topographic feature, and thus tries to smoothen the smaller scale temperature field induced by $A d v V$ (Fig. 8b). The large-scale circulation only partly follow the embayment of the Lambert Glacier, causing the larger scale advection patterns there. Cooling and warming patterns on the Antarctic Peninsula and in Marie Byrd Land are related to condensation at the upwind side (see Fig. 6c) and föhn on the lee side.

Figure 9d shows the advection of heat by the large-scale circulation of the ABL temperature deficit $\left(A d v H_{\boldsymbol{u}_{l s c} \delta \theta}\right)$. This frame shows most variability, partly reflecting the large spatial variability in ABL temperature deficit in Antarctica (Fig. 9h). Cooling and heating patterns match gradients in inversion strength along the large-scale wind. Above $2000 \mathrm{~m}$ in East Antarctica (Fig. 9a), the similarity between the patterns in $A d v H_{P}$ and $A d v H_{u_{l s c} \delta \theta}$ indicates that this component dominates the $A d v H$ variability there.

The advection by ABL wind of background temperature $\left(A d v H_{\delta \boldsymbol{u} \theta_{0}}\right)$ is primarily a heating contribution in the coastal zone (Fig. 9e). This represents downslope advection of potentially warmer air, driving a large-scale föhn effect.

Figure $9 \mathrm{f}$ shows advection of temperature deficit by ABL wind $\left(A d v H_{\delta \boldsymbol{u} \delta \theta}\right) . A d v H_{\delta \boldsymbol{u} \delta \theta}$ mostly cools the escarpment 
of East Antarctica, where the inversion strength is reduced by extensive mechanically driven vertical mixing. In contrast to the large-scale circulation, $\delta \boldsymbol{u}$ has a significant downslope component, and $A d v H_{\delta \boldsymbol{u} \delta \theta}$ can therefore maintain low-level cold air advection. Warming by $A d v H_{\delta \boldsymbol{u} \delta \theta}$ is found in regions where $\delta \boldsymbol{u}$ points into a location with a stronger inversion. Besides regions in the East Antarctica plateau with concave topography, such warming is found where the ice sheet is fringed by ice shelves.

\section{Results: summer}

\subsection{External heating and surface interactions}

The strong katabatic winds in the winter $\mathrm{ABL}$ are indirectly forced by a large surface radiation deficit. In the austral summer months December and January, net solar insolation brings the surface radiation budget into balance. The summer ABL is thus not dominated by katabatic flow. $S H D$ is thus largely reduced, as is visible in Fig. 10a, with cooling rates of on average $2 \mathrm{~K}$ per day. Over the ocean, $S H D$ is also small.

The cooling by longwave divergence $(L W D)$ has even less spatial variability (Fig. 10b). Over the ocean, $L W D$ is reduced on those locations where cloud top height is mostly above the ABL depth.

The heating or cooling by water phase changes is similar to winter (Fig. 10c). Over the ocean, the heat released by condensation is balanced by melt of falling snow near the surface. The small cooling spots along the coast are due to evaporation of precipitation in the adiabatically dried ABL. The heating by shortwave radiation divergence $(S W D)$ and convection $(C H D)$ are not shown. $S W D$ heats the ABL by about $1 \mathrm{~K}$ per day. $S W D$ is slightly larger over Antarctica than over the Southern Ocean. Evaluation of model results with satellite observations (Sect. 2) showed that the model underestimates total net SW absorption over the ice sheet, but still $S W D$ would be small. $C H D$ is less than $1 \mathrm{~K}$ per day over land, and on average $1 \mathrm{~K}$ per day over the ocean.

\subsection{Heat advection}

In absence of continuous surface cooling, the surface temperature deficit (Fig. 11a) is small in the austral summer. Katabatic winds and thus subsidence are weaker. Vertical heat advection (Fig. 11b) is still a net source of energy, but one order of magnitude smaller than during winter. Domes and convex ridges are again locations with slightly stronger warming by $A d v H$. Even more than in winter, $A d v H$ counterbalances $A d v V$ (Fig. 11c). $A d v V$ and $A d v H$ are thus mostly determined by topographical induced convergence or divergence of the surface wind field and the resulting vertical winds. The large-scale circulation in the ABL is rather independent of season (Van den Broeke and Van Lipzig, 2003), but ABL deviations are strongly reduced.
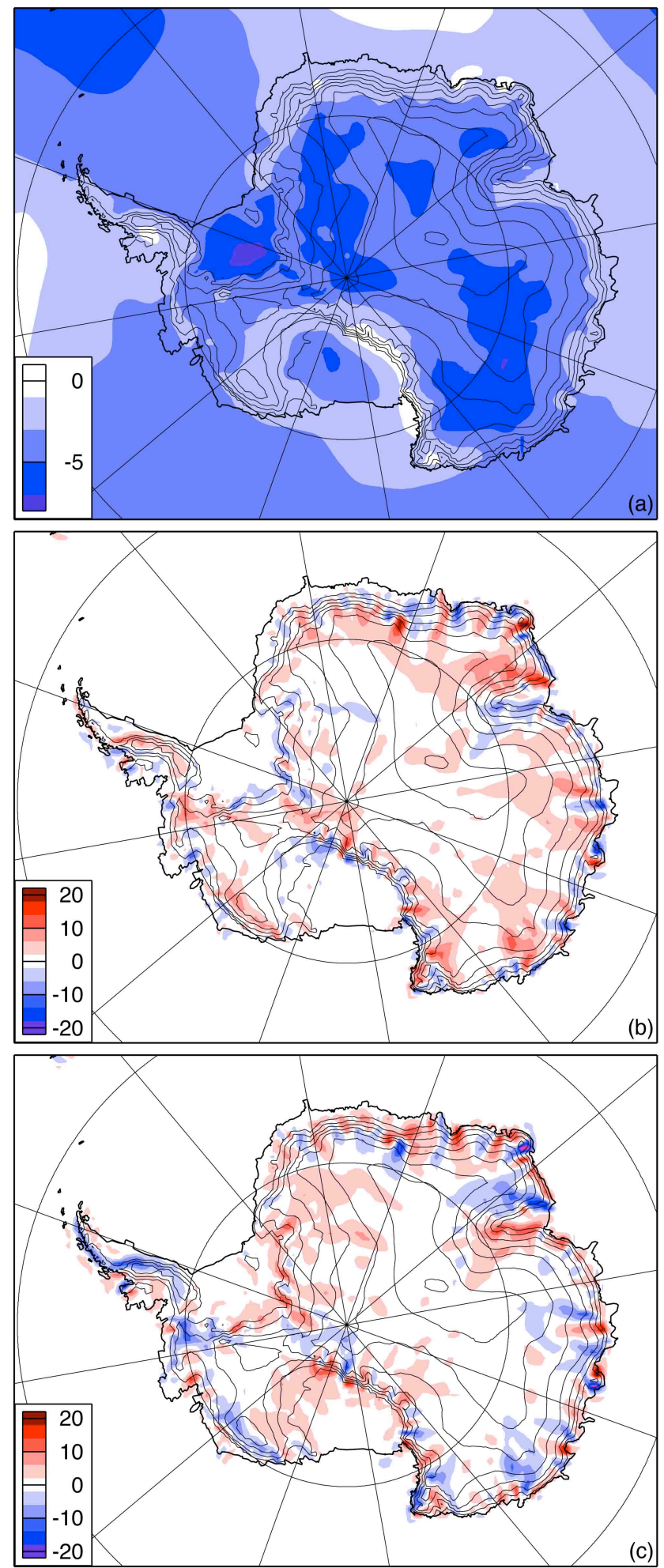

Fig. 11. Summer averages of (a) ABL mean potential temperature deficit in $\mathrm{K}$, (b) Vertical heat advection $(A d v V)$ in $\mathrm{K}$ per day and (c) Horizontal (along-slope) heat advection $(A d v H)$ in $\mathrm{K}$ per day. 
$A d v H_{u_{l s c} \theta_{0}}$ is the main contributor to $A d v H$, and nearly equals its winter value (Fig. 9c). The other four contributions $\left(A d v H_{S T}, A d v H_{\boldsymbol{u}_{l s c} \delta \theta}, A d v H_{\delta \boldsymbol{u} \theta_{0}}\right.$ and $\left.A d v H_{\delta \boldsymbol{u} \delta \theta}\right)$ also resemble the winter spatial patterns, but the magnitudes are reduced by a factor of three on average.

\section{Summary and conclusions}

The heat budget of the Antarctic ABL is investigated using output of the regional atmospheric climate model RACMO2/ANT.

During winter, divergence of the sensible heat flux ( $S H D)$ and long-wave radiation flux ( $L W D$ ) are the primary cooling terms over the ice sheet. Both terms are spatially smooth, and $S H D$ is largely controlled by ABL depth. Averaged over the ice sheet, vertical heat advection $(A d v V)$ by subsidence is the primary heat source. Horizontal, i.e. along-slope, heat advection $(A d v H)$ is a secondary heating term. $A d v V$ and $A d v H$ show counterbalancing spatial patterns. At domes and ridges, where the topography is convex, the $\mathrm{ABL}$ wind field diverges so that $\mathrm{ABL}$ is heated by subsidence $(A d v V)$. In response, $A d v H$ cools at these locations. Conversely, in valleys, which have concave topography, the $\mathrm{ABL}$ wind converges; subsidence is reduced or even reverted, and $A d v V$ can become a cooling term. The temperature deficit thus increases there along the prevailing katabatic wind, and $A d v H$ warms the ABL. The extremes of $A d v V$ and $A d v H$ are found at topography with a length scale of $\sim 100 \mathrm{~km}$, the minimum size of topography that was properly resolved. ABL temperature, however, is also influenced by larger features, because larger features provide a longer path for $A d v H$ to act on temperature.

$A d v H$ is predominantly determined by the climatological wind and temperature fields, as can be expected for a process that is governed by topography. In the interior of East Antarctica, $A d v H$ is mainly determined by the advection of the $\mathrm{ABL}$ temperature deficit along the large-scale and $\mathrm{ABL}$ wind. Along the coast, advection of background temperature along the large-scale wind mainly determines the patterns in $A d v H$. This is because the large-scale wind and background temperature are unable to adjust to topographic features smaller than a few hundred $\mathrm{km}$.

During summer, the ABL temperature deficit is restricted to the nocturnal ABL. Warming by $A d v V$ and $A d v H$ are therefore much reduced in magnitude compared to winter, but spatial patterns are found to be similar.

These processes govern the temperature in the Antarctic ABL. A next step will be to investigate how these processes might alter in a changing climate, and thus how Antarctic near surface temperatures might change in the future.

\section{References}

Bromwich, D. H. and Fogt, R. L.: Strong Trends in the Skill of the ERA-40 and NCEP-NCAR Reanalyses in the High and Midlatitudes of the Southern Hemisphere, 1958-2001, J. Climate, 17, 4603-4619, 2004.

King, J. C., Connolley, W. M., and Derbyshire, S. H.: Sensitivity of Modelled Antarctic Climate to Surface and Boundary-Layer Flux Parameterizations, Q. J. Roy. Meteor. Soc., 127, 779-794, 2001.

Parish, T. R. and Cassano, J. J.: The Role of Katabatic Winds on the Antarctic Surface Wind Regime, Mon. Weather Rev., 131, 317-333, 2003.

Reijmer, C. H., Van Meijgaard, E., and Van den Broeke, M. R.: Evaluation of temperature and wind over Antarctica in a Regional Atmospheric Climate Model using 1 year of automatic weather station data and upper air observations, J. Geophys. Res., 110, D04103, doi:10.1029/2004JD005234, 2005.

Sterl, A.: On the (In)homogeneity of Reanalysis Products, J. Climate, 17, 3866-3873, 2004.

Stull, R. B.: An Introduction to Boundary Layer Meteorology, Kluwer Academic Publishers, 1988.

Undén, P., Rontu, L., Järvinen, H., et al.: The High Resolution Limited Area Model, Hirlam-5 scientific documentation, Swedish Meteorological and Hydrological Institute, Norrköping, Sweden, 2002.

Van As, D. and Van den Broeke, M. R.: Structure and dynamics of the summertime atmospheric boundary layer over the Antarctic Plateau: 2. Heat, moisture and momentum budgets, J. Geophys. Res., 111, D07103 doi:10.1029/2005JD006956, 2006.

Van de Berg, W. J., Van den Broeke, M. R., Reijmer, C. H., and Van Meijgaard, E.: Reassessment of the Antarctic surface mass balance using calibrated output of a regional atmospheric climate model, J. Geophys. Res., 111, doi:10.1029/2005JD006495, 2006.

Van de Berg, W. J., Van den Broeke, M. R., and Van Meijgaard, E.: Heat budget of the East Antarctic lower atmosphere derived from a regional atmospheric climate model, J. Geophys. Res., 112, D23101, doi:10.1029/2007JD008613, 2007.

Van den Broeke, M. R. and Van Lipzig, N. P. M.: Factors Controlling the Near-Surface Wind Field in Antarctica, Mon. Weather Rev., 131, 733-743, 2003.

Van den Broeke, M. R., Van Lipzig, N. P. M., and Van Meijgaard, E.: Momentum Budget of the East Antarctic Atmospheric Boundary Layer: Results of a Regional Climate Model Budget of the East Antarctic Atmospheric Boundary Layer: Results of a Regional Climate Model, J. Atmos. Sci., 59, 3117-3129, 2002.

White, P. W.: Part IV, Physical processes (CY23R4), Tech. Rep., European Centre For Medium-Range Weather Forecasts (ECMWF), 2001.

Zhang, Y., Rossow, W. B., Lacis, A. A., Oinas, V., and Mishchenko, M. I.: Calculation of radiative fluxes from the surface to top of atmosphere based on ISCCP and other global data sets: Refinements of the radiative transfer model and the input data, J. Geophys. Res., 109, D19105, doi:10.1029/2003JD004457, 2004

Edited by: R. Greve 